\title{
Letters
}

Website: bmj.com

Email: letters@bmj.com

\section{Doctors and nurses}

\section{Let's celebrate the difference between doctors and nurses}

EDITOR-The BMJ issue on doctors and nurses does not define or describe nursing but repeatedly talks about nurses doing doctors' jobs. ${ }^{1}$ The predominance of the theme of substitution of doctors' work by nurses undermines the ideas of multidisciplinary working, cooperation, and collaboration that also feature in this issue. Unless doctors are clearer about the role of nurses in health care, discussions about their relationships with nurses will appear patronising and uninformed.

The importance of difference emphasised by Davies frames the debate. ${ }^{2}$ This idea should be the foundation of the utility of the relationship between doctors and nurses. But following Davies's paper, every article strives to seek common ground between medicine and nursing, with nurses seen primarily as an economic substitute. This continues until the final personal view by Radcliffe, which, with admirable symmetry, closes the debate opened by Davies. ${ }^{3}$ But, between their two papers, who is actually celebrating the difference?

As a general practitioner I do expect nurses to do the things I dislike doing more cheaply and more efficiently. I expect nurses to take on the tasks they do better than me and to share the tasks they do equally well. Sometimes nurses are less costly because nurse training is shorter and the opportunity to specialise can therefore come earlier. We should be thinking of the most cost effective services we can provide.

If the relation between medicine and nursing is really to bear fruit then medicine will have to recognise more explicitly that nurse training prepares different professionals. In their letter Laurent et al epitomise the need for a more penetrating conceptualisation of the nursing role in talking about substituting nurses for doctors to improve quality and optimise the (cost) effectiveness. ${ }^{4}$

Davies highlights the importance of difference-it is not what people have in common but their differences that make collaborative work more powerful. I look forward to a BMJ and Nursing Times collaboration that celebrates the difference.

Patrick White clinical senior lecturer

Department of General Practice and Primary Care, Guy's, King's and St Thomas's School of Medicine, London SE5 9PJ

patrick.white@kcl.ac.uk
1 Doctors and nurses. Special joint issue with the Nursing Times. BMJ 2000;320 (7241). (15 April.) 2 Davies C. Getting health professionals to work together. BMJ 2000;320:1021-2. (15 April.)

3 Radcliffe M. Doctors and nurses: new game, same result. BMJ 2000;320:1085. (15 April.)

4 Laurent M, Sergison M, Halliwell S, Sibbald B. Evidence based substitution of doctors by nurses in primary care? BMJ 2000;320:1078. (15 April.)

Teamwork is not about everyone trying to do the same job

EDITOR-Beecham reports the government's 10 point challenge on nursing skills. Effective teamwork between doctors and nurses need not entail one group taking over the work of the other. Members of genuine teams have distinct roles and do not compete to do the same tasks. Not everyone working on an aeroplane participates in flying it. Bus conductors and drivers do not fight over who tings the bell and who holds the steering wheel.

Why, then, is it that the only way anyone seems able to perceive doctors and nurses working more closely is by nurses taking on the role of a doctor? Anyone who has been in hospital knows that good nursing is priceless, promoting healing in its widest sense. The thrust of much of the debate, and the implication of the proposals put forward by the health secretary, Alan Milburn, is that "traditional" nursing cannot be a rewarding career. No wonder recruitment is difficult. I find former nurses everywhere. Most are caring people who have left reluctantly because they feel their basic nursing is undervalued-by managers, by some doctors, but also by the nursing profession itself.

Mr Milburn has implied that nurses should not be seen as working for doctors. There is definitely a role for specialist nurses, and I would support a fast track for able nurses into and through medical school. But we are approaching a situation in some departments where a doctor cannot ask a nurse to do anything. Some new style nurses are more interested in listening to the patient's chest than making sure he or she has something to vomit into. Frequently, nursing observations are not followed through lack of staff or time. This is not teamwork: it is doctors and nurses unproductively duplicating work. Meanwhile we see junior doctors, who are temporary team members wherever they work, treated as unwelcome intruders into someone else's territory. I know of many doctors working long hours on units where they are not even provided with a stool to sit on, while other "team members" enjoy whole offices, sitting rooms, and a secure supply of chocolates.

I hope for three things to come from this debate.

Firstly, as it is no longer the role of nurses to work for doctors, we need to create another group of healthcare workers whose role this is. Perhaps this is a niche for (paid) medical students.

Secondly, we should value the different contributions of individuals within healthcare teams.

Thirdly, we all need to learn the true meaning of teamwork.

Derek Roskell consultant pathologist Oxford Radcliffe Hospitals NHS Trust, John Radcliffe Hospital, Oxford OX3 9DU

1 Beecham L. UK health secretary wants to liberate nurses' talents. BMJ 2000;320:1025. (15 April.)

\section{Who will do nurses' current tasks?}

EDITOR-It is all well and good for the government to say that new roles should be undertaken by nurses, but who is going to do the current jobs that nurses are required to do? ? $^{1}$ Do we simply employ more care assistants, as they are cheaper than qualified staff, and return to the two tier system in nursing that the conversion of enrolled nurses was supposed to remove?

Junior doctors are stretched, and reallocating some of their roles will undoubtedly ease their workload. But what about the ward nurses? There can often be only one or two trained nurses caring for up to 40 patients at a time. Will more money be made available to increase these shortfalls before dumping others' workloads on an already overburdened service?

Dave Anderson staff nurse

Intensive Care, William Harvey Hospital, Ashford, Kent TN24 0LZ

tsb1@globalnet.co.uk

1 Beecham L. UK health secretary wants to liberate nurses' talents. BMJ 2000;320:1025. (15 April.)

\section{Why liberation is necessary}

EDITOR-I should like to suggest a few answers to the questions posed in the Editor's choice of the special joint issue with the Nursing Times: "Why ... is a government minister having to liberate nurses 52 years into the health service? What's he liberating them from?" Perhaps the minister recognises that nurses need to be freed from the white, male, middle class culture that has so dominated health care for the past century 
or more. The analogy drawn by the editor between nurses and prostitutes to illustrate the differing balance of responsibility and power-that nurses have the former but not the latter, the converse of what he perceives as the case for prostitutes-only confirms that he subscribes to this culture. The audience ("university educated") would naturally realise that prostitutes have no power. It lies in the hands of the men that use them.

Smith then describes the divisions between doctors and nurses as including sex, background, philosophy, training, regulation, money, status, and intelligence. There is no doubt that doctors receive more money and have greater status, but where is the evidence that they come from different backgrounds, are less regulated, and (most insultingly) are of higher intelligence? These divisions are a product of the male dominated, paternalistic culture that has prevailed for the 52 years of the national health service.

If nurses increasingly take on the tasks that "bore doctors" this would be an inappropriate use of highly skilled healthcare staff. If, however, they become the initial point of contact in the majority of consultations it is likely that patients, as suggested by the papers in the joint issue, will enjoy increasing satisfaction. Should nurses eventually take over the $80 \%$ of first contacts that is projected, we can look forward to the end of the recruitment and retention crisis among general practitioners that we hear so much about.

The divisions that Smith lists only serve to reinforce stereotypical behaviour. As long as doctors persist in treating nurses as " $\mathrm{B}$ list" players in primary care such behavour will be perpetuated. It is time that doctors climbed down from their ivory towers and recognised their fellow professionals as integral team players.

Jayne Lunn practice nurse and clinical governance facilitator

West Anglia Resource Centre, Upwell, Wisbech PE14 9BT

nwapcag@dial.pipex.com

1 Editor's choice. Doctors and nurses: a new dance? BMJ 2000;320 (7241). (15 April.)

\section{Intelligence is not in the eye of the beholder}

EDITOR-The editor seems to be confusing intelligence with an ability to pass science examinations. ${ }^{1}$ Scoring highly in science A levels, a prerequisite to getting into medical school, does not mean that you are intelligent. It means that you are good at passing exams. The intelligence required to be a competent and caring doctor (or nurse) encompasses much more, as indicated by the need to overhaul medical undergraduate programmes in the United Kingdom.

The editor also assumes that people who apply to do nursing are not also able to apply for medical school. I know of at least three nursing colleagues who chose nursing, not medicine, as a career, although they were all offered places in "top" medical schools. I maintain that it is not differing levels of intelligence that divide doctors and nurses; rather, it is the perception, held by some doctors, that nurses are intellectually inferior that is the real barrier.

Francine M Cheater senior lecturer (nursing) Department of General Practice and Primary Health Care, University of Leicester, Leicester General Hospital, Leicester LE5 4PW fc8@le.ac.uk

1 Editor's choice. Doctors and nurses: a new dance? $B M$ 2000;320 (7241). (15 April)

\section{Sex difference? Is there one?}

EDITOR-An important point that seems to have been missed in discussions of the roles of doctors and nurses and sex stereotypes is that medical students have been predominantly female for at least five years in this medical school and in most others that I have been in contact with. ${ }^{1}$ This trend shows no sign of abating. This is not to do with the medical school's admissions procedure-a similar proportion (about two thirds) of students applying from school are women. There seems to be a feeling in the schools and possibly society at large that a girl who is doing well in science based subjects would do well to go in for medicine rather than pure sciences or engineering. There is no longer a sex difference between junior doctors and nurses, and this will also soon be the case for specialist registrars and higher categories.

Norman Vetter reader in public health

Department of Epidemiology and Public Health, University of Wales College of Medicine, Cardiff CF4 4XL

Vetter@cf.ac.uk

1 Editor's choice. Doctors and nurses: a new dance? $B M$ 2000;320 (7241). (15 April.)

\section{Medical profession is no longer patriarch} of professions

EDITOR-Alcolado in his personal view on nurse practitioners and the future of general practice does not credit colleagues in primary care with the ability to deliver services effectively. ${ }^{1}$ Many general practitioners provide care beyond that defined by the general medical services contract by working collaboratively with primary care teams that will increasingly include nurse practitioners in future. Advanced nursing roles are an important development in primary care, but the implications have yet to be fully appreciated. Only now, as changes affect the interface between primary and secondary care, do some doctors perceive a threat.

As a nurse practitioner I do not carry out "tasks" but can provide most people's primary care needs for most of the time. I am not a gatekeeper to the general practitioner but a clinician whose experience and degree level training have equipped me to distinguish serious illness when it occurs, to manage common chronic and self limiting illness, and to form long term relationships with patients and families. Although it may be difficult to distinguish my practice from that of a general practitioner, I am not a doctor substitute, and patients actively exercise their choice to see me. The assumption that everyone wants to see a doctor when they are ill is insupportable, and evidence is accumulating that they welcome the opportunity to consult a nurse. ${ }^{23}$

It is not inevitable that patients lose the choice of seeing a general practitioner. The medical profession must seek solutions to recruitment problems in unattractive areas, but not by expecting the nursing profession to step aside to preserve the status quo. Where is the evidence that a traditional medical degree followed by vocational training is the only adequate preparation for general practice, where, as Alcolado concedes, much morbidity has a social cause? There is scope for widening the entry gate to vocational education and valuing the interpersonal skills of nurses alongside the clinical skills of doctors, in a multidisciplinary educational model, to enable doctors and nurses to become primary care practitioners.

Nurse practitioners are aware of their obligation to address questions of external validation and professional regulation, and work is under way to resolve such issues. Primary care is fortunate to have nurses who are prepared to pioneer innovative roles alongside doctors who acknowledge that the medical profession is no longer the patriarch of professions. Such collegiate and collaborative relationships improve teamwork to the benefit of professionals and patients.

Anne Price primary care nurse practitioner Ashgrove Surgery, Pontypridd CF37 2DR anne.price@shs.swan.ac.uk

1 Alcolado J. Nurse practitioners and the future of general practice. BMJ 2000;320:1084. (15 April.)

2 Reveley $\mathrm{S}$. The role of the triage nurse in general medical practice: an analysis of the role. J Adv Nurs 1998;28:3: 584-91.

3 Chapple A, Rogers A, Macdonald W, Sergison M. Patients' perceptions of changing professional boundaries and the perceptions of changing professional boundaries and the
future of 'nurse-led' services. Primary Health Care Res Dev 2000;1:51-9.

\section{Length of consultation is important for patient satisfaction}

EDITOR-The message from the three papers by Shum et al, Kinnersley et al, and Venning et al is the same..$^{1-3}$ Patients express greater satisfaction with practitioners, whether nurses or doctors, who spend longer over their consultations and give them more information. The cost effectiveness of nurse practitioners seeing minor illness is yet to be established.

The real issue is the length of the consultation, not whether suitably trained nurses can identify minor and largely self limiting conditions as well as a general practitioner. This new work takes these scarce and highly skilled professionals away from other work that they are already good at and diverts them to something that general practitioners can do already. About $20 \%$ of cases seen by the nurses had to be seen by a general practitioner at the same visit anyway, so why not cut out the middle man? Keep the doctors seeing the acute illnesses, but use the resources that might be used on training these nurses to increase consulta- 
tion time of general practitioners who have already been trained. It is, however, worth considering the related point that spending longer on minor illnesses at the expense of something else might not be an appropriate use of scarce resources anyway.

Peter Brindle locum general practitioner Bristol BS6 7SF

peter.brindle@lineone.net

1 Shum C, Humphreys A, Wheeler D, Cochrane M, Skoda S, Clement $S$. Nurse management of patients with minor illClement S. Nurse management of patients with minor illnesses in general practice: multicentre, rand
controlled trial. $B M J$ 2000; 320:1038-43. (15 April.)

2 controlled trial. BMJ 2000; 320:1038-43. (15 April.) Turton P, et al. Randomised controlled trial of nurse practitioner versus general practitioner care for patients requesting "same day" consultations in primary care. $B M$ 2000;320:1043-8. (15 April.)

3 Venning P, Durie A, Roland M, Roberts C, Leese B. Randomised controlled trial comparing cost effectiveness of general practitioners and nurse practitioners in primary care. BMJ 2000; 320:1048-53. (15 April.)

\section{Data do not provide conclusions on nurse} practitioners

EDITOR-We work alongside a large group of emergency nurse practitioners in a positive relationship and were interested in the paper by Shum et al on nurses treating minor illness. ${ }^{1}$ They concluded that practice nurses offer an effective service for minor illnesses, but the data provided do not support this.

Almost the entire effect seen $(2.2 / 100)$ is a result of the greater length of time that the nurses spent with the patients. The multiple regression leaves an almost negligibly significant difference $(\mathrm{P}=0.047)$ once this is taken into account

Shum et al state that they used an intention to treat analysis, but it does not include those patients who did not wish to see a nurse in the first place $(n=206)$. This allows for selection bias, as the enrolled patients then formed a subset who may have preferred to see a nurse.

Despite their possible equal satisfaction with the consultation, only $7.5 \%$ of those that saw a nurse wanted to see a nurse again, and five times as many $(31.5 \%)$ would rather see the doctor next time. In contrast, of those patients who saw the general practitioner half would still rather see the general practitioner, and only $2 \%$ wanted to see a nurse next time. These data sit uncomfortably with the satisfaction scale results, and the validity of the questionnaire is open to question, as it was originally developed to compare satisfaction with different general practitioners, not between different types of healthcare providers. ${ }^{2}$ "Comparison between health professional groups should be undertaken with caution."

Information bias distorts many of the findings of the study - the lack of blinding of the intervention style (doctor or nurse) to the observer (patient). We should also consider that the number of subjects in the study was in fact just the 24 individuals being assessed (five nurses and 19 general practitioners), each intervention was by an individual practitioner, and outcome was satisfaction with that individual's style of consultation, thus the true sample size was only 24 .
Shum et al should take into account that the "clinically effective service" they conclude is offered by nurses also needs to detect rare illnesses as well as generate satisfaction with outcome in self limiting illness. The future care pathway for minor illness is uncertain and may include nurse practitioners, but this paper has contributed little evidence to support such a change in practice.

Peter Leman consultant

Jane Terris consultant

Accident and Emergency Department, St Thomas's Hospital, London SE1 7EH

1 Shum C, Humphreys A, Wheeler D, Cochrane M, Skoda S, Clement S. Nurse management of patients with minor illnesses in general practice: multicentre, randor controlled trial. BMJ 2000;320:1038-43. (15 April.)

Baker R. Consultation satisfaction questionnaire: development of a questionnaire to assess patients' satisfactovelopcont 1990:40:487-90.

3 Poulton B. Use of the consultation satisfaction questionnaire to examine patients' satisfaction with general practiioners and community nurses: reliability, replicability an discriminant validity. BrJ Gen Pract 1996;46:26-31.

\section{Author's reply to Brindle and Leman and} Terris

EDITOR-Much but not all of the greater satisfaction with nurses was related to longer consultation times. Our data imply that this satisfaction is at least as high as that with general practitioners and would probably remain comparable even with shorter consultations. Although the consultation satisfaction questionnaire was originally devised for doctors, its use for nurse consultations has been validated, ${ }^{1}$ and it seemed to be the most appropriate of the currently available tools when selecting outcome measures.

Bias could be introduced when a large proportion of eligible patients decline to participate in a trial-the 206 who declined were only $10 \%$ of all eligible patients. We could not have included them in the intention to treat analysis because in a standard clinical trial design those who decline do not have outcome data collected on them.

The satisfaction ratings and the patients' indications of which type of professional they would prefer to see in the future are two different issues. With the satisfaction scale, patients were rating their satisfaction with the consultation they had just had, whereas in answering the question about future preference, patients in the doctors' group were expressing a view about a form of care that they probably had not experienced. Patients tend to like existing services. ${ }^{2}$ The fact that more patients in the nurses' group $(69 \%)$ than the doctors' group (53\%) would be happy to see a nurse in future shows that experience of a new form of care can alter perceptions of it. Furthermore, the question of future preference may be affected by factors such as continuity of carer and the expectation of seeing a doctor when ill.

Clinical effectiveness is difficult to measure, particularly for management issues in general practice. We discussed various study limitations, including the issue of rare events. However, our data suggest that the nurse service is clinically effective.

Service provision is different from showing that a type of service is potentially effective. We found that nearly $20 \%$ of patients seen by the nurse had to be seen by a general practitioner as well. Whether this is sustainable in terms of cost effectiveness is still not clear. Our data suggest that referral rates may fall as nurses become more experienced: in the second half of the trial only $17.7 \%$ of nurses' patients had to be seen by the doctor, compared with $21.3 \%$ in the first half.

Cost effectiveness goes beyond the immediate cost of a nurse or general practitioner. We should take into account factors such as the improvements that could be made by changing the way current services are provided. For example, in minor illness there might be little to choose in terms of cost between a nurse and a general practitioner, but doctors' time might be better used in seeing patients with more complex problems or extending other services.

Chau Shum general practitioner Walderslade Village Surgery, Walderslade ME5 9LD

1 Poulton B. Use of the consultation satisfaction questionnaire to examine patients' satisfaction with general practitioners and community nurses.reliability, replicability, and discriminant validity. BrJ Gen Pract 1996;46:26-31.

2 Porter M, Macintyre S. What is, must be best: a research note on conservative or deferential responses to antenatal care provision. Soc Sci Med 1984;19:1197-200.

\section{Doctors and nurses need to collaborate}

EDITOR-On completing reading the special issue on doctors and nurses I came away with these messages: doctors and nurses are different, working together is difficult, nobody really knows how to do it anyway, and we need more research. ${ }^{1}$ There is not much to argue with there.

What can be done? We have introduced shared learning for medical and nursing students in years one and two of their training (with the Florence Nightingale School of Nursing).

It may be too late to put postgraduate programmes in operation if undergraduate education is not responding likewise by providing opportunities for interprofessional learning. It may be more important that undergraduate changes are appreciable and valued. We then have a chance of success on the grounds of a diminishing return of undesirable attitudes, which are difficult to change.

Our approach has been to focus on communication and basic clinical skills for medical and nursing students. Mixed groups of students learn and work collaboratively on patient centred tasks and present work together at the end of sessions. So this is not about a medical student "sitting in" with nurses or vice versa.

What students, clinicians, and lecturers think so far is difficult to tell at this stage. But reluctance, resistance, guarded interest, and perceived low value are being replaced by cautious acceptance and continuing support for further developments. 
How have we done it? Initially a joint research project concentrated on communication skills and effective team working. Clinical skills needed for infection control were introduced in year 2. We gained support after two years to timetable the course centrally. We model good practice by cofacilitating where possible. We responded to feedback from students and facilitators.

What did we need? Support from our bosses and deans; a commitment to work together and respect for each other's difficulties; only slightly less than missionary zeal and will; and the ability to deal with criticism from people with personal agendas and barely hidden prejudices.

Why are we doing it? Doctors and nurses are the predominent groups in professional health care. They spend most of their time working together in clinical settings. This is not about nurses learning to do doctors' tasks for them. We aim for learners to come away with increased understanding of each other, patients' needs, and shared clinical problems. It is still early days.

\section{Elaine Gill head}

Communication Skills Unit, Chantler Clinical Skills Centre, Guy's, King's and St Thomas's School of Biomedical Sciences, Medicine and Dentistry, London SE1 9RT

1 Doctors and nurses. Special joint issue with the Nursing Times. BMJ 2000;320 (7241). (15 April)

\section{Doing it together with PAMs}

EDITOR-We welcomed the joint edition of the BMI and Nursing Times. ${ }^{1}$ Here we describe how delivery of care in paediatric gastroenterology has been enhanced by cooperative care in which doctors, nurses, and "PAMs" (professionals allied to medicine) have become equal partners.

We have established a multidisciplinary service for children with elimination disorders called "the Pro-Motion team." Children with severe constipation are admitted under the care of the ward sister (MM) and play specialist (AS) for disimpaction with polyethylene glycol (Movicol) and behaviour modification. School age children are visited and supported by a specialist school nurse (NB) and preschool children by a health visitor $(\mathrm{CN})$. A clinical nurse specialist in child and family psychiatry (AD) sees children with emotional problems. When parents are able to take part in the behaviour modification programme the children are discharged to the care of a community children's nurse (GC), with visits from NB and CN. Consultants-a paediatric gastroenterologist (DCAC), specialist registrars (AK, RV), and staff grade (MS)-are increasingly involved in a consultative role rather than driving the service. The level of support and expertise provided by professionals, including nurses and a play specialist, from a variety of backgrounds and different NHS trusts has been directly responsible for attracting competitive research funding.

An alternative model of service delivery, provided by $\mathrm{AD}$ and DCAC in the Holistic Paediatric Gastro-Enterology Clinic, is in keeping with the spirit of the special $N T / B M J$ joint issue. Children with gastrointestinal symptoms in whom there is thought to be a major psychological component are seen by the clinical nurse specialist and the gastroenterologist together. A medical examination is followed by a detailed psychological history as well as the medical history. A joint diagnostic formulation and management plan is developed with the family, which may include diet, pharmacological therapy, and stress management. A joint letter is sent to the referring doctor. Depending on the outcome, follow up may be with one specialist but is usually with both. They have seen about 50 families in this way. Formal audit of the service will be required, but the initial experience of the professionals involved is that substantial progress has been made with families who were "challenging" or difficult to help.

The bringing together of biomedical and nursing expertise with PAMs in a "one stop" consultation, without stigmatisation of the family, may be one area in which the nurse consultant role proves its worth.

Nina Bunce specialist school nurse

Gill Cunningham community children's nurse Alison Davies clinical nurse specialist in child and family psychiatry

Cynthia Nemeth health visitor

Mary Styles staff grade paediatrics

Sussex Weald and Downs NHS Trust, Chichester PO19 4FX

Arun Kundu paediatric specialist registrar

Melanie Munn paediatric ward sister

Angela Scrase play specialist

Rowena Vincent paediatric specialist registrar

David C A Candy consultant paediatric

gastroenterologist

david.candy@rws-tr.sthames.nhs.uk

Royal West Sussex NHS Trust, St Richard's

Hospital, Chichester PO19 4SE

1 Doctors and nurses. Special joint issue with the Nursing Times. BMJ 2000;320 (7241). (15 April.)

\section{Implications of CJD data need to be clear before release}

EDITOR-Reports surrounding the analysis of tonsillar and appendix tissue for evidence of variant Creutzfeldt-Jakob disease (vCJD) have highlighted the difficulty faced by scientists in presenting complex and emotive medical information to the public. Great care is needed, especially when the implications of results are uncertain.

The discovery of prion protein in an appendix removed from a patient in Torbay in 1995 before the onset of clinical signs of new variant Creutzfeldt-Jakob disease (nvCJD) raised the possibility of diagnosing cases before patients are aware that they are infected. A programme of testing several thousand pathological specimens of appendixes and tonsils was started. The intention was to test whether nvCJD prion protein might be present in any of them and, if it was, to assess its significance.

Preliminary results from this study were recently released to the press. No cases were found in any of the 3000 samples of tonsil and appendix tissue studied. ${ }^{3}$ But these preliminary results are insufficient to indicate whether a substantial number of people are affected with the condition, and much further work is needed.

The press coverage has further shown the difficulty faced by the news media in presenting results of studies into this condition. News coverage of the study emphasised its importance and the implications for the NHS of finding as few as two cases. This raised expectations in the public in advance of the release of these results and led to a real risk that the public were overly reassured by the negative results when they were released. Leading political and medical figures have needed to emphasise that insufficient information is available to make conclusions.

As a profession we are faced with difficult choices regarding the release of data early from studies. However, we do have control over this information and it is therefore our responsibility to ensure that its implications are clear. This may mean delaying publication until an adequate sample size has been reached or further analyses are available.

Andrew Thornett clinical research fellow Department of Psychiatry, University of Southampton, Southampton SO14 OYG eanador@soton.ac.uk

Competing interests: None declared.

1 Dobson R. First results of vCJD survey show no signs of prion. BMJ 200;320:1226. (6 Mav.)

2 Brooks A. Surgical specimens to be tested for new variant CJD. BMJ 1998;317:617.

3 BBC News Online. CJD tests show no epidemic. 28 April 2000

\section{Effect of on-site mental health professionals}

\section{Longer trials are needed}

EDITOR-The systematic review by Bower and Sibbald of on-site mental health professionals was a welcome addition to the literature on the effectiveness of the talking therapies in primary care. ${ }^{1}$ In view of the effect on consultation rates, prescribing of psychotropic drugs, and referrals to secondary care, the conclusion drawn was that the evidence for a direct effect was strongest in relation to general practitioner referrals to secondary care providers.

Six randomised controlled trials of direct effects on referrals were identified. Three were reported as showing referrals to be significantly reduced. Although some of the limitations of the studies were discussed, each of the six trials is flawed in terms of being able to generalise to everyday primary care

One trial was described as showing a significant reduction in referrals when the stated $\mathrm{P}$ value was 0.56 , which is not significant. $^{2}$ Furthermore, the therapy offered was from a psychiatrist based in primary care rather than the more usual British model using a counsellor or psychologist. Just 47 patients were recruited to this trial, but, with a duration of seven months, it was the longest of the three "positive" trials.

The other two randomised controlled trials showed reduced referrals only because those receiving usual general practitioner 
care had a referral rate to secondary care of over $50 \% .{ }^{3}$ This was an unusually high proportion, which placed counselling in an unduly favourable light.

The three positive trials lasted just six weeks, ${ }^{3}$ four months, ${ }^{4}$ and seven months. ${ }^{2}$ The shorter the duration, the more likely it is that any effect observed on reducing referrals may simply be deferment of referral rather than satisfactory treatment on-site. Trials of at least one year are probably needed. Just one of the trials in the review covered a one year period, but that failed to show any reduction in referrals. ${ }^{5}$

The review also identified six nonrandomised controlled studies reporting the indirect effect on referrals from the practice as a whole. However, two were in non-peer reviewed publications, one entailed the intervention of a psychiatrist, and the remaining three either were not significant or did not state a $P$ value.

Simply to state that three out of the six trials showed significantly reduced referrals may be misleading without more critical comment. Long term randomised controlled trials, incorporating health economic analysis, are urgently needed to study the effects of counsellors and psychologists in primary care. Every primary care group needs this information to guide purchasing decisions.

Mark Ashworth research fellow

Guy's, King's and St Thomas's Department of General Practice, Kings College London, London SE11 6SP

Bower P, Sibbald B. Systematic review of the effect of on-site mental health professionals on the clinical behaviour or general practitioners. BMJ 2000;320:614-7. (4 March.)

2 Catalan J, Gath D, Anastasiades P, Bond A, Day A, Hall L Evaluation of a brief psychological treatment for emotional disorders in primary care. Psychol Med 1991;21:1013-8

3 Boot D, Gillies P, Fenelon J, Reubin R, Wilkins M, Gray P. Evaluation of the short-term impact of counseling in general practice. Patient Educ Couns 1994;24:79-89.

4 ral prace. Patient Educ Couns 1994,24.79-89. controlled trial. Patient Educ Couns 1997;32:219-30.

5 Corney R. The effectiveness of attached social workers in the management of depressed female patients in general practice. Psychol Med 1984; (monograph suppl 6):1-47.

\section{Authors' reply}

EDITOR-Ashworth is right to say that primary care groups need high quality information to make purchasing decisions. This is one reason why we believe that our systematic review of the available research into on-site mental health professionals will prove valuable to clinicians and managers. Even when the evidence base is weak, as in the case of on-site mental health professionals, such a review can inform decision making by showing that the benefits or disadvantages attributed to a service are not well established and may not materialise.

Ashworth questions whether it is appropriate to conclude that on-site mental health professionals may have their greatest impact on the referral rates to providers of secondary care, given the poor quality of available research. Specifically, he recommends that we ignore studies that $(a)$ do not adhere to the "usual British model" of care, $(b)$ are of borderline statistical significance, $(c)$ have not been published in peer reviewed journals, or $(d)$ have findings which look "unusual."

Firstly, it is far from clear whether differences between services in the type of mental health professional (for example, psychiatrists versus psychologists) will have a different effect on primary care providers. The evidence basis is insufficient, and further research is needed.

Secondly, the interpretation of results at the boundary of significance is complex, but ignoring the effect is as risky as attaching undue importance to it. As more information becomes available, a better approximation of the true effect can be achieved through formal meta-analysis.

Thirdly and fourthly, we adhered to Cochrane standards regarding study inclusion and quality assessment. Excluding papers not published in peer reviewed journals or with results which look unusual is liable to introduce bias and is not recommended.

We share Ashworth's view that longer term trials and health economics analyses are needed before a definitive answer can be stated. One advantage of Cochrane reviews is that they are regularly updated, allowing examination of new evidence. In the meantime, existing research suggests that the effect of on-site mental health professionals on referral rates was the most consistent and striking and is likely to have a marked effect on estimates of the cost effectiveness of counselling.

Peter Bower research fellow

peter.bower@man.ac.uk

Bonnie Sibbald professor of health services research National Primary Care Research and Development Centre, University of Manchester, Manchester M13 9PL

\section{Harvey I, Nelson S, Lyons R, Unwin C, Monaghan S, Peter T. A randomized controlled trial and economic evaluation of counselling in primary care. Br J Gen Pract 1998:48:1043-8.}

\section{Treating hyperhidrosis}

\section{Excision of axillary tissue may be more effective}

EDITOR-We read with interest the editorial on hyperhidrosis by Collin and Whatling. They suggest that botulinum toxin should be the treatment of choice for axillary hyperhidrosis. Early studies have shown that intradermal injection of botulinum toxin produces an effective but temporary inhibition of sweating. ${ }^{2}$ The therapeutic effects of botulinum toxin have been reported to last three to eight months in healthy volunteers. ${ }^{3}$ There is some evidence to suggest that higher doses of botulinum toxin may produce a satisfactory reduction in sweating for as long as one year in some patients. Continued treatment is inevitable in order to maintain anhidrosis. Repeated injections and hospital visits may be unpleasant and inconvenient for the patient and expensive for the NHS.
Collin and Whatling fail to mention the role of surgical excision of axillary tissue for the treatment of hyperhidrosis. Breach described a simple method of surgical excision of subcutaneous axillary tissue that produced a high satisfaction rate among the reported case group of 25 patients (50 axillae) at follow up after one year. ${ }^{5}$ The method described uses three parallel transverse incisions to the axilla, through which the subcutaneous axillary tissue is removed. This technique carries a low complication rate and produces aesthetic scars with negligible functional deficit. Many of the patients attend after thorascopic sympathectomy which resolved their palmar, but not axillary, hyperhidrosis. Surgical excision of axillary tissue remains an important treatment modality for a large proportion of hyperhidrotic patients. It has the ability to provide a permanent and satisfactory solution to a frustrating problem. It is not as yet a redundant method of treatment.

J L Atkins senior house officer, plastic surgery

P E M Butler consultant plastic surgeon

Royal Free Hospital, London NW3 2QG

1 Collin J, Whatling P. Treating hyperhidrosis. $B M$ J 2000;320:1221-2. (6 May)

2 Schnider P, Binder M, Auff E, Kittler H, Berger T, Walsh TN. Double-blind trial of botulinum A toxin for the treatment of focal hyperhidrosis of the palms. $B r J$ Dermate 1997;136:548-52.

2 Nauman MP Flocker EB Botulinum toxin for palmar hyperhidrosis. Lancet 1997;349:252.

for palmar hyperhidrosis. Lancet 1997,949:252. Heckmann M. Follow up of patients with axillar hyperhidrosis after bo tol 1998;134:1298-9.

5 Breach NM. Axillary hyperhidrosis: surgical cure with aesthetic scars. Ann R Coll Surg Engl 1979;61:295-7.

\section{Iontophoresis should be tried before} other treatments

EDITOR-We read with interest the editorial by Collin and Whatling about the treatment options for hyperhidrosis. ${ }^{1}$ Hyperhidrosis is a socially debilitating, and patients with the condition often do not do well with topical treatment with aluminium chloride hexahydrate or anticholinergic drugs.

Dermatologists are often presented with this problem. Most patients have the hyperhidrosis localised to their hands and feet. Although thoracoscopic sympathectic trunkotomy and botulinum toxin injections may be effective, they can produce serious side effects, some of which may be irreversible. Dermatology centres offer a further treatment option.

Iontophoresis is easy to perform, effective in about $90 \%$ of patients in two studies with 54 and 30 participants, free of hazardous side effects, and well accepted by almost all patients. ${ }^{23}$ Contraindications to treatment are pregnancy, cardiac pacemakers, and metal orthopaedic implants. Almost complete cessation of sweating occurs after four treatments of about 10 minutes over two to three weeks. The machines cost considerably less than $£ 1000$, and, since tap water is used to conduct the electric current, this is a cheap alternative treatment compared with botulinum toxin or surgery. This should primarily be offered to patients with palmarplantar hyperhidrosis, whereas the more aggressive treatments 
should be reserved for those who do not respond or have axillary problems that are less amenable to treatment with iontophoresis.

Patients presenting with palmar-plantar hidrosis deserve a trial of all conservative treatments including iontophoresis before more aggressive techniques such as botulinum toxin or thorascopic sympathetic trunkotomy are tried.

R Murphy specialist registrar dermatology C I Harrington consultant dermatologist

Royal Hallamshire Hospital, Sheffield S10 2JF

1 Collin J, Whatling P. Treating hyperhidrosis. BMJ 2000;320:1221-2.(6 May)

Odia S, Vocks E, Rakoski J, Ring J. Successful treatment of dyshidrotic hand eczema using tap water iontophoresis with pulsed direct current. Acta Derm Venereol 1996;76:472-4.

3 Reinauer S, Neusser A, Schauf G, Holzle E. Pulsed direct current iontophoresis as a possible new treatment for hyperhidrosis. Hautarzt 1995;46:543-7

\section{Anticholinergic drugs were not mentioned}

EDITOR-We disagree with the subtitle of the editorial by Collin and Whatling-namely, that surgery and botulinum toxin are treatments of choice in severe cases of hyperhidrosis. ${ }^{1}$ They dismiss conventional medical treatment with anticholinergic drugs as inconvenient, unpleasant, and temporary, and they say that patients usually stop using anticholinergic drugs because of a dry mouth.

The truth is exactly the opposite. Surgery is only rarely necessary, and the editorial quite properly warns of numerous surgical pitfalls, which include recurrence of hyperhidrosis, almost certain impotence, compensatory sweating, permanent neurological damage from anoxia, and death (their words). Botulinum toxin, which they recommend for axillary or plantar hyperhidrosis, requires 12 injections per axilla and 24-36 injections per foot. Even this horrendous procedure gives only 11 months' relief, and antibody formation may reduce long term efficiency.

The logical treatment is with anticholinergic drugs. We have used glycopyrronium bromide (Robinul), $2 \mathrm{mg}$ up to three times daily, for 25 years with great success. Most patients we see are young women, whose hyperhidrosis is ruining their lives. This drug greatly improves their quality of life, and the inevitable dry mouth is accepted unreservedly.

Young women do not suffer any other unwanted effects, although it is obvious that older men (who do not as a rule present to us with hyperhidrosis) may well have problems with vision and micturition. The North East Thames Regional Drug Information Service could find no evidence of any long term side effects; some patients have used it for years.

The sting is in the tail. The drug was manufactured in the United Kingdom and licensed as an antispasmodic; it was quite inexpensive. Now it is available only from the United States, on a named patient basis, and the importer has recently doubled the price to $£ 72$ for $100 \times 2 \mathrm{mg}$. Patients believe that it is worth every penny, but perhaps some enterprising British drug manufacturer would care to manufacture it again.

Michael Klaber consultant dermatologist Broomfield Hospital, Chelmsford CM1 7ET F.Spoor@icrf.icnet.uk

Michael Catterall consultant dermatologist Basildon Hospital, Basildon SS16 5NI

1 Collin J, Whatling P. Treating hyperhidrosis. BMJ 2000;320:1221-2. (6 May.)

\section{Treatment options must be balanced against each other}

EDITOR-Someone not familiar with managing hyperhidrosis would think that the matter was all cut and dried after reading the editorial by Collin and Whatling. ${ }^{1}$ The authors are surgeons and are drawing on their experience of the patients referred to them from various colleagues who consider these patients possible candidates for surgery. This may be because these patients report that medical treatments are inconvenient, temporary, and unpleasant. But the topic is far broader than these selected patients.

There is a definite role for topical and systemic medication in a range of patients. These treatments are less absolute in their outcomes and also less permanent. They do, however, not produce compensatory sweating. For treatment of upper limb hyperhidrosis, compensatory sweating is commonly reported to occur in $50-70 \%$ of patients, with a figure of $97 \%$ in one series of 91 patients. ${ }^{2}$ The feet and trunk are the main affected sites.

A further aspect is gustatory sweating, which amounts to an outbreak of sweating on the smell or taste of food, reported in $50.7 \%$ of subjects in one series of 323 patients. $^{3}$ This does not equate with treatment failure, but should be emphasised before the operation. Collin and Whatling report an initial cure of $100 \%$, and it seems that this is maintained to a great extent for palmar hyperhidrosis. The results are less rewarding for axillary hyperhidrosis, however, where satisfaction rates after one year are as low as $33.3 \%$, in comparison with $66.7 \%$ for palmar sweating.

Surgery is a valuable option in this troublesome condition, but we should present a balanced picture of its virtues and not dismiss less aggressive forms of treatment.

David de Berker consultant dermatologist Bristol Dermatology Centre, Bristol Royal Infirmary, Bristol BS2 8HW

\section{Collin J, Whatling P. Treating hyperhidrosis. $B M /$ 2000;320:1221-2. (6 May) \\ 2 Chiou TS, Chen SC. Intermediate-term results of endoscopic transaxillary T2 sympathectomy for primary palmar hyperhidrosis. Br J Surg 1999;86:45-7. \\ 3 Herbst F, Plas EG, Fogger R, Fritsch A. Endoscopic thoracic sympathectomy for primary hyperhidrosis of the upper limbs. A critical analysis and long-term results of 480 operations. Ann Surg 1994; 220:86-90.}

\section{Author's reply}

EDITOR-Successful removal of axillary tissue through three parallel transverse incisions, as suggested by Atkins and Butler, certainly cures axillary hyperhidrosis. The complications are wound infection, abcess formation, skin necrosis, cutaneous anaes- thesia, scarring, keloid formation, and limitation of shoulder abduction.

Iontophoresis, as suggested by Murphy and Harrington, stops sweating by waterlogging the skin to block the sweat ducts. The same effect is produced by prolonged immersion in water. Ten minutes of iontophoresis in hospital involves expensive equipment, hours of commuting and waiting time, inconvenience, and travel costs. Immersion of hands and feet in bowls of warm water at home is cheaper, quicker, and more convenient and has no contraindications.

Anticholinergic drugs, as recommended by Klaber and Catterall, reduce sweating and provide some relief from hyperhidrosis. Their unwanted effects include reduced salivation with a dry mouth and impaired speech, taste, mastication, and swallowing; a dilated pupil, photophobia, blurred vision, and acute glaucoma; impaired micturition, reduced bronchial secretions, and constipation; confusion, nausea, vomiting, and giddiness; tachycardia, palpitations, and arrythmias. Nine months' supply of glycopyrronium bromide costs $£ 592$ (\$905), excluding physician and dispensing fees, compared with £165 (\$252) for bilateral axillary injection of botulinum toxin.

The total lifetime cost of unilateral thoracoscopic sympathectomy is £1913 (\$2927). Thoracoscopic sympathectomy performed as a separate operation on each side has slight risks of serious complications or death. The incidence and severity of compensatory hyperhidrosis increase with the area of skin sympathetically denervated. Unilateral sympathetic trunkotomy between the T1 and T2 ganglia guarantees a dry handshake and solves the problem for many patients. It is rarely followed by compensatory hyperhidrosis. Bilateral trunkotomy often induces compensatory hyperhidrosis, but it is seldom troublesome. To cure axillary hyperhidrosis, T2 and T3 sympathetic ganglionectomy is necessary; after bilateral surgery compensatory hyperhidrosis is usual and sometimes bothersome. Pathological gustatory sweating is an uncommon complication of thoracic sympathectomy. Its high reported incidence in some series may be attributable to diathermy injury to the $\mathrm{T} 1$ sympathetic ganglion.

For disabling palmar hyperhidrosis, thoracoscopic sympathetic trunkotomy is the treatment of choice. Axillary hyperhidrosis is cured for around nine months by injection of botulinum toxin. Lumbar sympathectomy has no place in the treatment of pedal hyperhidrosis since ejaculatory impotence and anorgasmia are likely consequences. Pedal botulinum toxin injection is unacceptable to most patients and some doctors. The palliation provided by anticholinergic drugs, iontophoresis, and aluminium chloride hexahydrate is balanced by their expense, inconvenience, and unwanted pharmacological effects.

Jack Collin consultant surgeon

Nuffield Department of Surgery, John Radcliffe

Hospital, Oxford OX3 9DU 


\section{Quality of randomised controlled trials in head injury}

\section{Statistical power can be increased}

EDITOR-We agree with Dickinson et al ${ }^{1}$ that larger and better designed randomised controlled trials are necessary to detect benefits of treatment in head injury. ${ }^{2}$ But increasing the sample size is not the only solution to show efficacy. The statistical power of a study can also be improved by randomising the same number of patients but taking prognostic factors, such as age or Glasgow coma scale, into account

Firstly, one might limit the inclusion of patients to those with an intermediate prognosis-for example, between $20 \%$ and $80 \%$ probability of a favourable outcome. ${ }^{3}$ This leads to a focus on patients for whom treatment effects can be well determined. For the same power, a reduction in sample size of $30 \%$ might be achievable. ${ }^{3}$ After showing efficacy in the intermediate risk group, additional funding may be raised more easily to study patients with a poorer or better prognosis. Note that this reasoning assumes that the relative effect of a treatment is constant across risk groups. This is in contrast to the assumption of an absolute effect of $5 \%$ as discussed by Dickinson et al. Such an absolute effect is comparatively large at a baseline incidence of $20 \%$, as indicated by an odds ratio of 0.71 for the comparison of an incidence of $15 \%$ versus 20\%. In contrast, the odds ratio is 0.82 for the same absolute effect at $50 \%$ baseline incidence ( $45 \% v 50 \%)$. The absolute effect of $5 \%$ is more easily detected at a baseline incidence of $20 \%$, while a relative effect such as an odds ratio of 0.71 is more easily detected at an incidence of $50 \%$. So the assumption of an absolute or relative effect is crucial in reasoning about power and inclusion criteria.

Secondly, even if inclusion would be limited to patients at intermediate risk, heterogeneity will remain regarding the probability of a favourable outcome. Predictive characteristics which account for this heterogeneity can be adjusted for in the analysis, which will increase the statistical power to detect a treatment effect. ${ }^{4}$ In an analysis of patients with acute myocardial infarction, the potential reduction in sample size was $12 \%$ by adjustment for age.

Besides dealing with heterogeneity, we may also consider restricting data collection to the essential variables, such that larger numbers of patients are accrued at the same costs. We hope that the strategies here proposed will be applied in the study of therapy for head injury, together with an increase in funding.

\section{Chantal W P M Hukkelhoven epidemiologist}

hukkelhoven@mgz.fgg.eur.nl

Ewout W Steyerberg epidemiologist

Andrew I R Maas neurosurgeon

Erasmus Medical Centre Rotterdam, 3000 DR

Rotterdam, Netherlands

Dickinson K, Bunn F, Wentz R, Edwards P, Roberts I. Size and quality of randomised controlled trials in head injury: review of published studies. BMJ 2000;320:1308-11. (13 May.)
2 Maas AIR, Steyerberg EW, Murray GD, Bullock R Baethmann A, Marshall LF, Teasdale GM. Why have recent trials of neuroprotective agents in head injury failed to show convincing efficacy? A pragmatic analysis an theoretical considerations. Neurosurgery 1999;44:1286-98. 3 Machado SG, Murray GD, Teasdale GM. Evaluation of designs for clinical trials of neuroprotective agents in head injury. J Neurotraum 1999;16:1131-8.

4 Robinson LD, Jewell NP. Some surprising results about covariate adjustment in logistic-regression models. Int Sto Rev 1991;59:227-40.

5 Steyerberg EW, Bossuyt PMM, Lee KL. Clinical trials in acute myocardial infarction: Should we adjust for baseline characteristics? Am Heart J 2000;139:745-51.

\section{More trials are needed}

EDITOR-Dickinson et al are to be congratulated for highlighting the deficiencies in research into head injury. ${ }^{1}$ The situation is no better for children with head injuries. The American Academy of Pediatrics issued a report based on extensive literature review of 108 articles on head injury in children. ${ }^{2}$ The academy concluded that the literature on mild head trauma does not provide a sufficient scientific basis for evidence based recommendations about most of the key issues in clinical management.

To address this issue, a multicentre study to develop a set of clinical decision rules for the management of head injured children is now in its third month of data collection. All children with head injuries at nine hospitals in the north west of England are seen by the attending doctor using a tailored study pro forma. Forty clinical correlates relating to symptoms, signs, and investigations are entered. We are collecting patients at the rate of 1300 per month. Once 15000 forms have been collected, all data on admission, neurosurgical intervention, and mortality will be collected. A set of clinical decision rules will then be derived using recursive partitioning (as with the Ottawa ankle guidelines). The guidelines will then be validated in a further 15000 patients.

This is the first time that such an approach has been used in the management of head injury, and I agree with Dickinson et al that it is only by large, well conducted trials that we are going to advance the evidence base in head injury

Joel Desmond cardiothoracic senior house officer Wythenshawe Hospital, Manchester M23 9LT joeldesmond@doctors.org.uk

1 Dickinson K, Bunn F, Wentz R, Edwards P, Roberts I. Size and quality of randomised controlled trials in head injury: and quality of randomised controlled trials in head injury:
review of published studies. BMJ 2000;320:1308-11. review of
(13 Mav.)

2 Homer CJ, Kleinman L. Technical report: minor head injury in children. Pediatrics 1999;104:e78. (www pediatrics.org/cgi/content/full/104/6/e78)

\section{Transfusion transmitted infection}

Did authors systematically underestimate risks of transfusion?

EDITOR-There are three different ways of estimating the residual risk of infections transmitted by blood transfusion: follow up of recipients of the blood; screening donated blood with more sensitive tests than routinely used (for example, nucleic acid amplification); and estimating the number of undetectable infectious units from seroconversions of repeat donors.

In their prospective follow up study of 5579 out of 9220 patients Regan et al did not detect a single transfusion transmitted infection. ${ }^{1}$ In view of estimated risks of lower than 1 in 100000 for transmission of hepatitis $\mathrm{B}$ and $\mathrm{C}$ viruses and lower than 1 in 1 million for transmission of HIV, however, such a result was not unexpected. The estimate would change dramatically if only one of the 657 participants not followed up because of death or of the 2734 participants not followed up because they were too ill to participate died or was too ill because of transfusion transmitted infection.

Unfortunately, the same possible bias underlies all methods of estimating the number of undetectable infectious units on the basis of the seroconversion of repeat donors. If the donor is too ill to return for a further donation (or is diagnosed with clinically apparent infection and told to stop donating blood) seroconversion is not detected by the blood centre and the residual risk is systematically underestimated.

Even estimations based on results obtained with the polymerase chain reaction tend to underestimate the risk: Schüttler et al showed that blood preparations negative for infection by the polymerase chain reaction can transmit infection with hepatitis $\mathrm{C}$ virus. ${ }^{2}$ One can only estimate a correction factor for this possible bias if one assumes that donors have no preference to donate immediately after infection when blood is still negative by the polymerase chain reaction.

All methods for estimating the residual risk of transfusion transmitted infection contain a possible bias that may result in underestimation of the true risk.

Gregor Caspari research fellow

Institute of Clinical Chemistry, Justus Liebig University, 35392 Giessen, Germany gregor.j.caspari@viro.med.uni-giessen.de

1 Regan FAM, Hewitt P, Barbara JAJ, Contreras M on behal of the current TTI Study Group. Prospective investigation of transfusion transmitted infection in recipients of ove 20000 units of blood. BMJ 2000;320:403-6. (12 February.) 2 Schüttler CG, Caspari G, Jursch CA, Willems WR, Gerlich WH, Schaefer S. Hepatitis C transmission by a blood donation negative in nucleic acid amplification tests for viral RNA. Lancet 2000;355:41-2.

\section{Authors' reply}

EDITOR-We agree that all methods of estimating the residual risk of transfusion transmitted infections have some flaws. Caspari suggests that the estimates in our study would change dramatically if even one transmission was missed among the 657 participants who died or the 2734 not followed up because they were too ill. $\mathrm{He}$ suggests that these patients were rendered ill by transmitted infections, and hence bias was introduced against us finding transfusion transmitted infections in the population we followed up.

Firstly, it is known that recipients of half of blood transfusions die of underlying disease within one year (J Mortimer, 
personal communication). Despite our attempts to exclude groups of patients likely to die before follow up, 657 did so.

Secondly, death or severe morbidity from HIV or hepatitis $\mathrm{C}$ virus infection within nine months of these infections being acquired is unlikely in patients who are not immunosuppressed (immunosuppressed patients were excluded from the study at the outset). Hepatitis B might cause death within nine months, but it would be unusual if such a dramatic infection in a patient given a transfusion was not notified to the National Blood Service for investigation.

We were aware that hepatitis B might cause severe morbidity (sufficient to preclude the patient from attending follow up) but go unreported to the National Blood Service. Early in the study we therefore attempted to obtain causes of death and precise diagnoses from general practitioners of patients unable to attend for follow up, but it proved impossible to obtain information in most cases (general practitioners were understandably too busy). Information obtained from patients or relatives when follow up was declined indicated that patients were usually ill or had died from their underlying conditions; hepatitis was not implicated. This, however, is incomplete anecdotal information, and the possibility that a transfusion transmitted hepatitis B virus infection may have gone undetected, thus resulting in an underestimation of the true risk, cannot be excluded.

Fiona Regan locum consultant in donor and tissue services

Pat Hewitt lead consultant in transfusion microbiology John Barbara lead scientist in transfusion

microbiology

National Blood Service, North London Centre, London NW9 5BG

patricia.hewitt@nbs.nhs.uk

\section{National service framework's financial implications are huge}

EDITOR-We are delighted that tools for assessment of risk of cardiovascular disease have been addressed in a whole issue of the $B M J{ }^{1}$ It is unfortunate that so many calculators (Sheffield mark 2; New Zealand mark 2) cannot agree on definitions and may not in fact give the same results for each patient. ${ }^{2}$ We have compared 10 risk algorithms, and, while the Sheffield tables underestimate risk in patients with diabetes at $3 \%$ per year, the revised (but not the old) New Zealand guidelines match the performance of other guidelines: British, European, University College London, as recommended in the national service framework for coronary heart disease.

The only European risk calculator based on the Munster heart study has not been mentioned in the national service framework. ${ }^{2}$ It is applicable to cases of secondary prevention and factors for risks owing to family history and triglycerides, and, in addition, its original database is more modern than the rather dated United States population study (Framingham).
We agree with Montgomery et al and Isles et al in the special issue that computerised calculators offer no advantage over card based methods and are more difficult to use. They are also more subject to systematic bias induced by biological variation in the input variables than card based systems.

The United Kingdom has a large burden of coronary heart disease as a result of both hyperlipidaemia and hypertension. The editorial by Jackson, which says that the evaluation of risk factors should include measuring blood pressure but not cholesterol testing, follows false logic. ${ }^{4}$ The cost of measuring blood pressure properly (£15) far exceeds the cost of blood tests for full lipid profiles including the concentrations of low density lipoprotein cholesterol (£3-5) and total cholesterol (£1-2). This is not obvious only because costs in staff time are neglected as these are treated as a marginal cost and not as a finite limited resource. The implications of the national service framework for nursing time are such that such calculations are no longer tenable.

The challenge has now been laid down to the medical profession to deliver drug treatment for secondary prevention at $2.5 \%$ per year risk and at a higher risk threshold for primary prevention of 3\% per year. The financial implications for general practice, drug budgets, pathology laboratories, and secondary sector preventive and classical cardiological services are huge. This programme is capable of absorbing a substantial part of the rise in the NHS budget even if it is properly funded. If it is not, it will fail.

Anthony S Wierzbicki senior lecturer in chemical pathology

St Thomas's Hospital, London SE1 7EH

Timothy M Reynolds professor of chemical pathology Queen's Hospital, Burton-on-Trent DE13 0RB

Professor Reynolds and Dr Wierzbicki have been paid for giving talks, been reimbursed for attending conferences, and received funds for clinical research in cardiovascular disease by manufacturers of lipid lowering and antihypertensive drugs. 2000;320:659-724. (11 March)

Wierzbicki AS, Reynolds TM, Gill K, Alg S, Crook MA. A comparison of algorithms for initiation of lipid lowerin therapy in primary prevention of coronary heart disease $J$ Cardiovascular Risk 2000;7:63-73

3 Department of Health. National service framework for corom Department of Health. National service framework for coronary heart disease. London: Departm

(hitp.// distedoh.gov.uk/nst/chd.htm). Jackson R. Guidelines on preventing cardiovascula disease in clinical practice. BMJ 2000; 320:659-61.
(11 March.)

\section{Advance directives}

\section{Three questions should be asked}

EDITOR-The paper by Diggory and Judd ${ }^{1}$ reporting the response to their questionnaire survey shows that there is an encouraging awareness of advance directives among the responding NHS trusts but very little evidence that trusts make any routine provision for recording the existence and whereabouts of an advance directive, prepared when the patient was both calm and competent. ${ }^{1}$
The time to gather this information is on admission when name, address, date of birth, religion, and preferred name, etc are being recorded. Three simple questions added to the admission form would go a long way to alerting hospital staff to a (legally binding) directive that might otherwise be overlooked:

(1) Do you have an advance directive (living will)? yes/no

(2) Where is it kept? With general practitioner? yes/no

At home? yes/no

(3) If patient was admitted unconscious, has an advance directive card been looked for and found in patient's belongings? yes/no

Asking these questions on admission rather than later might give the many patients who are currently unaware of advance directives an opportunity for a calm discussion with hospital staff. To raise the subject later-for example, when they are about to sign a consent form for treatmentwould create unnecessary alarm and even confusion with a last will and testament.

Roger Hole retired urologist

Wynd House, Hutton Rudby, North Yorkshire TS15 0ES

Mr Hole is a member of the Voluntary Euthanasia Society and Doctors for Assisted Dying.

1 Diggory P, Judd M. Advance directives: questionnaire survey of NHS trusts. BMJ 2000;320:24-5. (1 January.)

\section{Maybe national guidelines are needed}

EDITOR-Perhaps the most interesting result of the survey by Diggory and Judd on advance directives was that three quarters of the NHS trusts responding to their questionnaire were in favour of national guidelines, which suggests that more trusts would consider addressing the issue if national guidelines were available.

One factor that might influence the NHS leadership to take action on national guidelines would be the expected economic benefits resulting from much greater use of advance directives. Recently, I saw a study conducted by the department of family medicine at Jefferson Medical College in Philadelphia, which showed that when the records of 474 Medicare patients who had died in hospital (in 1990, 1991, and 1992) were reviewed it was discovered that the mean inpatient charges for the 342 patients without documentation of a discussion of advance directives was more than three times that of the 132 patients with such documentation (\$95305v\$30 478). ${ }^{2}$

If a mentally competent terminally ill adult wishes to complete an advance directive (possibly to hasten his or her inevitable death with the aid of a medical team), why not encourage this? The patient gets what he or she wants, and society saves money that would otherwise be spent on expensive and, most important, unwanted end of life care.

Michael Irwin chairman

Doctors for Assisted Dying, Suite 64, 2 Old

Brompton Road, London SW7 3DQ 
1 Diggory P, Judd M. Advance directives: questionnaire survey of NHS trusts. BMJ 2000;320:24-5. (1 January.) 2 Chambers C, Diamond J, Perkel R, Lasch L. Relationship of advance directives to hospital charges in a Medicare population. Arch Intern Med 1994;154:541-7.

\section{Legal issues need clarification}

EDITOR-Diggory and Judd highlight inconsistencies in understanding of the legal issues around advance directives and suggest that national guidelines would encourage trusts to develop local policies to improve understanding and compliance with the law.' Enquiries to the BMA from doctors and lawyers show similar confusion about the legally binding nature of advance directives.

The BMA welcomes the government's recent statement of the legal position that, as a general point of law and medical practice, all adults have the right to consent to or refuse medical treatment, and advance statements are a means for patients to exercise that right by anticipating a time when they may lose the capacity to make or communicate a decision. ${ }^{2}$ The government is satisfied that the guidance contained in case law, together with the BMA's code of practice, ${ }^{3}$ is sufficient to provide clarity and flexibility without the need to introduce legislation governing advance statements at the current time. In response to this and Diggory and Judd, the BMA has placed its code of practice on the BMA website (www.bma.org. uk) with a new introduction to update on legal developments.

Michael Wilks chairman

Medical Ethics Committee, BMA, London WC1H 9JP

gromano-critchley@bma.org.uk

1 Diggory P, Judd M. Advance directives: questionnaire survey of NHS trusts. BMJ 2000; 320:24-25. (1 January.)

2 Lord High Chancellor. Making decisions. London: Lord Chancellor's Department, October 1999.

3 British Medical Association. Advance statements about medical treatment. London: BMA, 1995

\section{Advance directives are not legally binding}

EDITOR-Why does the BMJ consistently publish articles giving the mistaken impression that all advance directives are legally binding?' The case that people assume upholds their legality is that of a patient at Broadmoor hospital who refused to have an amputation for gangrene. The judgment stated that if his mental state should change and he become mentally incompetent, then his refusal of an amputation, made while competent and after being given an explanation of the possible consequences of that refusal, remained valid. I agree with this judgment, which is very different from saying all advance directives are legally binding.

The medical profession has moved from a paternalistic position of "doctor knows best" to one in which the patient gives informed consent. For consent to be valid the patient must understand both the expected benefits of the proposed treatment and the possible adverse consequences. If informed consent for treatment is right, then it is equally right, both morally and logically, that refusal of treatment should be equally informed. But informed refusal of treatment can be valid only if the specific facts pertaining to the current situation are available. It is likely that living wills will be made many years prior to mental incompetence, when details of the conditions specified-including possible treatments available-cannot be foreseen.

In many scenarios a legally binding living will could bring about the distressing situation that the testator was trying to avoid. For example, a patient may state that surgery must not be performed if terminal cancer is present, but palliative surgery may be indicated in terminal bowel cancer, not to prolong life, but to relieve the distressing symptoms associated with unrelieved bowel obstruction. In such a case a legally binding "living will" will prohibit doctors from providing the most appropriate palliative care available.

Michael Jarmulowicz consultant histopathologist Royal Free Hospital, London NW3 2OG mjarmulowicz@compuserve.com

1 Diggory P, Judd M. Advance directives: questionnaire survey of NHS trusts. BMJ 2000;320:24-5. (1 January.)

\section{Good education prepares people for} death

EdITOR-As general practitioners of 50 years' collective experience and as professional lifelong BMA members (albeit disenfranchised because there is no local branch), we feel compelled to write after the publication of two articles on dying earlier this year. ${ }^{12}$

We find it sad that members of a noble profession are seemingly pushing so hard to organise death, on a "well if we can't beat it, lets join it" basis. The suggestion that doctors are duty bound to follow to the letter an advance refusal of treatment is wrong. According to Finnis, the law firmly and rightly holds that those who have undertaken to provide treatment or nourishment are not absolved from their duty by the patient's adamant refusal, if that refusal is either incompetent or unlawful. ${ }^{3}$ A refusal that is motivated by the intent to commit suicide is unlawful, even though suicide itself is not a criminal offence; that is why assistance, and agreements to assist, in suicide are criminal offences. ${ }^{3}$

We applaud Smith's attempts at normalising dying and removing Western taboos, but we are horrified at the way he tries to stage manage the whole process. ${ }^{2}$ We cannot plan to deal with death in a tidy manner without being guilty of killing others or ourselves. Life and death march hand in hand every day, and a good education prepares young people for death, as well as for life (as stated at the headmasters' conference in 1994). Each of us should be ready for death at every moment of our lives.

"Do not be afraid of those who kill the body but cannot kill the soul; fear Him rather who can destroy both the body and soul in hell." ${ }^{4}$ The beginning of wisdom is fear of the Lord, but that fear ultimately is cast out by perfect love. In life and in death we are invited to join that perfect love on His terms, not ours.

We have sincere respect for those who find this last paragraph unacceptable but plead with them not to let their personal views cause immeasurable harm to society. However well intentioned they may be there is the serious threat that human frailty, being what it is, will distort their vision and promote state coercion and individual corruption.

Robert Hardie general practitioner

St Damian's Surgery, Melksham, Wiltshire SN12 6JN

RobClareHardie@aol.com

James Flood general practitioner

Littleton Panell Surgery, Nr Devizes, Wiltshire SN10 4EX

Susan Frankland general practitioner

St Damian's Surgery, Melksham, Wiltshire SN12 6JN

1 Diggory P, Judd M. Advance directives: questionnaire survey of NHS trusts. BMJ 2000;320:24-5. (1 January.)

2 Finnis J. "Living will" legislation. In: Gormally L, ed. Euthanasia: clinical practice and the law. London: Linacre Centre nasia: clinical practice and the law. Lon

3 Smith R. A good death. BMJ 2000;320:129-30. (15 January.)

4 Holy Bible. Matthew 10, 28

\section{Role of spironolactone in heart failure should be emphasised}

Editor-We welcome the article by Lonn and McKelvie on drug treatment in heart failure, ${ }^{1}$ which is a common and important condition. The article showed how good the evidence on the subject is. We were disappointed, however, that the role of spironolactone in improving outcomes was not discussed.

A randomised controlled trial consisting of 1663 patients showed significant benefits to patients with severe heart failure and a left ventricular ejection fraction of no more than $35 \%{ }^{2}$. These patients were already taking angiotensin converting enzyme inhibitors, loop diuretics, and, in most cases, digoxin. Ten per cent were also taking $\beta$ blockers. The spironolactone group had a relative risk of death over the 24 month study period of $0.70 \quad(95 \%$ confidence interval 0.60 to 0.82 ).

This equates to a number needed to treat of nine to prevent one death over the study period. The relative risk of admission to hospital was 0.65 ( 0.54 to 0.77 ; number needed to treat, 11). There was also a significant improvement in symptoms, assessed by the New York Heart Association functional class $(\mathrm{P}<0.001)$.

The importance of this message is perhaps increased as representatives from the pharmaceutical industry will not be informing general practitioners of this new evidence. This is in marked contrast to what is happening with angiotensin converting enzyme inhibitors and selective $\beta$ blockers. 
This omission was additionally unhelpful as the article was flagged as of specific interest to general practitioners. It is important to raise awareness in primary care of this inexpensive effective intervention as initiation and monitoring are quite simple for practitioners.

James Mapstone specialist registrar public health medicine

South Essex Health Authority, Brentwood CM13 3BE

James.Mapstone@sessex-ha.nthames.nhs.uk

Brian Houston general practitioner

Highlands Surgery, Leigh on Sea SS9 2UT

Mike Gogarty deputy director of public health

South Essex Health Authority, Brentwood

CM13 3BE

Mike.Gogarty@sessex-ha.nthames.nhs.uk

1 Lonn E, McKelvie R Drug treatment in heart failure. $B M J$ 2000;320:1188-92. (29 April.)

2 Pitt B, Zannad F, Remme WJ, Cody R, Castaigne A, Perez A, et al. The effect of spironolactone on morbidity and mortality in patients with severe heart failure. Randomized Aldactone Evaluation Study Investigators. $N$ Engl J Med 1999;341:709-17.

\section{Patient of gynaecologist who was struck off has been denied justice}

EDITOR-Roach has reported on the government inquiry into the serious malpractice of Rodney Ledward, a consultant gynaecologist in Kent who was struck off the medical register. ${ }^{1}$ In his news article Roach cited four cases that he presumably thought were of a particularly scandalous nature. One of these concerned a patient of mine, who was forced to agree to sterilisation as a condition of termination of pregnancy. In addition, she had to pay Rodney Ledward $£ 430$, although the operation was carried

\section{Advice to authors}

We prefer to receive all responses electronically, sent either directly to our website or to the editorial office as email or on a disk. Processing your letter will be delayed unless it arrives in an electronic form.

We are now posting all direct submissions to our website within 24 hours of receipt and our intention is to post all other electronic submissions there as well. All responses will be eligible for publication in the paper journal.

Responses should be under 400 words and relate to articles published in the preceding month. They should include $\leqslant 5$ references, in the Vancouver style, including one to the BMJ article to which they relate. We welcome illustrations.

Please supply each author's current appointment and full address, and a phone or fax number or email address for the corresponding author. We ask authors to declare any competing interest. Please send a stamped addressed envelope if you would like to know whether your letter has been accepted or rejected.

Letters will be edited and may be shortened.

bmj.com

letters@bmj.com

BMJ VOLUME $321 \quad 16$ SEPTEMBER 2000 bmj.com out from an NHS bed at the William Harvey Hospital in Ashford. Her uterus was perforated during the termination, although repaired during the sterilisation procedure.

Her "sympathetic response" from the trust said it was just as well she had had the second procedure so that the damage from the first could be repaired. She was encouraged to apply to a firm of solicitors to discuss the possibility of recompense, only to be told that she would have to spend more money on litigation with little realistic hope of getting any back. Her request to be included in the joint action to be organised by the police has been ignored. She has not received one penny of compensation, either from the NHS or from Mr Ledward, despite the huge sum spent on the prosecutions and the inquiry.

As a nation we seem to be incapable of providing the most elementary justice for those who have been wronged in this disgraceful affair

A R Crawfurd general practitioner Ivy Court, Tenterden, Kent TN30 6RB

1 Roach J. Management blamed over consultant's malpractice. BMJ 2000;320:1557. (10 June.)

\section{UK and German media differ over complementary medicine}

EDITOR-The media strongly influences the public's view of medical matters. ${ }^{1}$ Thus, we sought to determine the frequency and tone of reporting on medical topics in daily newspapers in the United Kingdom and Germany. The following eight newspapers were scanned for medical articles on eight randomly chosen working days in the summer of 1999: the Times, the Independent the Daily Telegraph, and the Guardian in the United Kingdom, and Frankfurter Allgemeine Zeitung, Süddeutsche Zeitung, Frankfurter Rundschau, and Die Welt in Germany. All articles relating to medical topics were extracted and categorised according to subject, length, and tone of article (critical, positive, or neutral).

A total of 256 newspaper articles were evaluated. The results of our analysis are summarised in the table. We identified 80 articles in the German newspapers and 176 in the British; thus, British newspapers seem to report on medical topics more than twice as often as German broadsheets. Articles in German papers are on average considerably longer and take a positive attitude more often than British ones. Drug treatment was the medical topic most frequently discussed in both countries (51 articles (64\%) in German newspapers and $97(55 \%)$ in British). Surgery was the second most commonly discussed medical topic in the UK newspapers (32 articles; 18\%). In Germany professional politics was the second most commonly discussed topic (11 articles; $14 \%$ ); this category included articles about the standing of the medical profes-
Reporting on medical topics by daily newspapers in the United Kingdom and Germany, 1999

\begin{tabular}{lcc} 
& \multicolumn{2}{c}{ Country } \\
\cline { 2 - 3 } & $\begin{array}{c}\text { United Kingdom } \\
(\mathbf{n = 1 7 6 )}\end{array}$ & $\begin{array}{c}\text { Germany } \\
(\mathbf{n}=\mathbf{8 0})\end{array}$ \\
\hline Mean No articles/day & 5.5 & 2.5 \\
\hline $\begin{array}{l}\text { Mean (SD) No } \\
\text { words/article }\end{array}$ & $130(26)$ & $325(41)$ \\
\hline Ratio of positive articles & 1.0 & 3.2
\end{tabular}

to critical articles*

*No of articles classed as positive divided by No of articles classed as negative. Neutral articles were excluded.

sion, health care, and social and economic systems-that is, issues not strictly about treating patients.

Because our particular interest is in complementary medicine, we also calculated the number of articles on this subject. We identified four articles in the German newspapers and 26 in the UK newspapers. In the United Kingdom the tone of these articles was unanimously positive $(100 \%)$ whereas most $(3 ; 75 \%)$ of the German articles on complementary medicine were critical

This analysis is, of course, limited by its small sample size, the short observation period, and the subjectivity of some of the end points. Yet it does suggest that, compared with German newspapers, British newspapers report more frequently on medical matters and generally have a more critical attitude (table). German newspapers frequently discuss medical professional politics, a subject that is almost totally absent from newspapers in the United Kingdom.

The proportion of articles about complementary medicine seems to be considerably larger in the United Kingdom (15\% v $5 \%$ ), and, in contrast to articles on medical matters in general, reporting on complementary medicine in the United Kingdom is overwhelmingly positive. In view of the fact that both healthcare professionals and the general public gain their knowledge of complementary medicine predominantly from the media, these findings may be important. ${ }^{23}$

E Ernst director

Department of Complementary Medicine, School

of Postgraduate Medicine and Health Sciences,

University of Exeter, Exeter EX2 4NT

E.Ernst@exeter.ac.uk

T Weihmayr general practitioner

Maillingerstrasse 3, 80636 Munich, Germany

1 Miles A. Radio and the comodification of natural medicine in Ecuador. Soc Sci Med 1998;47:2127-37.

2 Ernst E. Conventional attitudes towards the use of complementary therapies for asthma. Int J Alternative Complementary Med 1998;16:11-2.

3 Ernst E. Complementary therapies for asthma: what patients use. J Asthma 1998;35:667-71.

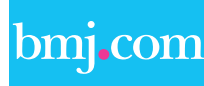

\section{Rapid responses}

Correspondence submitted electronically

is available on our website 